\title{
Sofosbuvir-based regimen is safe and effective for hepatitis $C$ infected patients with stage 4-5 chronic kidney disease: a systematic review and meta-analysis
}

Mingshu Li ${ }^{1,2}$, Jun Chen ${ }^{3}$, Zhixiong Fang ${ }^{4}$, Yi Li ${ }^{5^{*}}$ (1) and Qian Lin ${ }^{1 *}$

\begin{abstract}
Background: Whether sofosbuvir is suitable for hepatitis $\mathrm{C}$ virus (HCV) infected patients with severe renal impairment is inconclusive. This systematic review aims to evaluate the safety and effectiveness of SOF-based regimen in the setting of stage 4 and 5 chronic kidney disease (CKD).
\end{abstract}

Methods: We conducted a systematic literature search in PubMed, Web of Science, EMBASE and Google Scholar with searching strategy: (sofosbuvir OR Sovaldi OR Harvoni OR Epclusa OR Vosevi) AND (severe kidney impairment OR severe renal impairment OR end-stage renal disease OR dialysis OR renal failure OR ESRD OR renal insufficiency OR hepatorenal syndrome OR HRS). Sustained virological response (SVR12/24) rate and serious adverse event (SAE) rate with 95\% confidence intervals were aggregated. Subgroup analysis was implemented to evaluate the impact of treatment strategy and patient characteristics.

Results: Twenty-one studies met inclusion criteria, totaling 717 HCV infected patients with CKD stage 4 or 5 (58.4\% on dialysis). Pooled SVR12/24 was 97.1\% (95\% Cl 93.9-99.3\%), and SAE rate was 4.8\% (95\% Cl 2.1-10.3\%). There was no significant difference at SVR12/24 (97.1\% vs $96.2 \%, p=0.72)$ or SAE rate ( $8.8 \%$ vs $2.9 \%, p=0.13$ ) between subgroups applying full or decreased dose of sofosbuvir. Cirrhotic and non-cirrhotic patients achieved comparable sustained virological response (RR $0.93,95 \% \mathrm{Cl}$ 0.85-1.02). Four studies reported eGFR/serum creatinine pre- and post- treatment, with no significant modification.

Conclusions: Our study suggests SOF-based regimen might be used safely and effectively in patients living with HCV infection/stage 4-5 CKD, with normal and reduced dose of sofosbuvir. Prospective and well-controlled trials are needed to confirm these findings.

Trial registration: PROSPERO CRD42018107440.

Keywords: HCV infection, Stage 4-5 chronic kidney disease, Sofosbuvir, Dose, Meta-analysis

\footnotetext{
*Correspondence: liyi731128@csu.edu.cn; lin.qian@foxmail.com

${ }^{5}$ Department of Infectious Disease, The Second Xiangya Hospital of Central

South University, 139 Renmin Road, Changsha 410011, Hunan, China

${ }^{1}$ Xiangya School of Public Health, Central South University, 110 Xiangya

Road, Changsha 410078, Hunan, China

Full list of author information is available at the end of the article
}

(c) The Author(s). 2019 Open Access This article is distributed under the terms of the Creative Commons Attribution 4.0 International License (http://creativecommons.org/licenses/by/4.0/), which permits unrestricted use, distribution, and reproduction in any medium, provided you give appropriate credit to the original author(s) and the source, provide a link to the Creative Commons license, and indicate if changes were made. The Creative Commons Public Domain Dedication waiver (http://creativecommons.org/publicdomain/zero/1.0/) applies to the data made available in this article, unless otherwise stated. 


\section{Background}

Hepatitis $\mathrm{C}$ virus (HCV) infection and chronic kidney disease $(\mathrm{CKD})$ are epidemically correlated and clinically challenging.

It's estimated that 71 million people were chronically infected with $\mathrm{HCV}$ globally, and around $10 \%$ of them live with CKD $[1,2]$. For patients with CKD, particularly patients receiving hemodialysis, the incidence of $\mathrm{HCV}$ is much higher than general population, ranging from 3 to $50 \%$ [3]. HCV infection significantly elevates renal disease progression, and clearing HCV has proved to reduce liver related mortality/complications as well as risk of $\mathrm{HCV}$ transmission, therefore, $\mathrm{HCV}$ cure is of great importance to the patients with dual burden [4-6].

Sofosbuvir, a nonstructural NS5B polymerase inhibitor, was approved in 2013 and has revolutionized HCV treatment, enhancing the cure bar to above 90\% [7-9]. Sofosbuvir is mainly eliminated through renal pathway, and its use in patients with stage 4 and 5 CKD, defined according to KDIGO guidelines (GFR $<30 \mathrm{~mL} / \mathrm{min} / 1.73$ $\left.\mathrm{m}^{2}\right)$, is not indicated in label $[10,11]$. EASL Recommendations on Treatment of Hepatitis C 2018 suggested that sofosbuvir should be used with caution in patients with an eGFR $<30 \mathrm{ml} / \mathrm{min} / 1.73 \mathrm{~m}^{2}$ or with end-stage renal disease, only if alternative treatment is not available [12]. AASLD Guidance: Recommendations for testing, managing and treating hepatitis $\mathrm{C}$ mentioned the safe and effective dose of sofosbuvir in persons with an eGFR $<30$ $\mathrm{ml} / \mathrm{min}$ have not been established. However, there is accumulating evidence on use of sofosbuvir-based regimen in those with an eGFR $<30 \mathrm{ml} / \mathrm{min}$ [13]. Therefore, we performed a systematic review and meta-analysis to evaluate the safety and effectiveness of SOF-containing therapy for this group of patients.

\section{Methods}

\section{Literature search strategy}

We followed PRISMA (Preferred reporting items for systematic review and meta-analyses) statement guidelines to conduct this study [14]. Systematic literature search in PubMed, EMBASE, Web of science, and Google Scholar was performed by two reviewers independently, without publishing date or language limitation. The searching strategy used was: (sofosbuvir OR Sovaldi OR Harvoni OR Epclusa OR Vosevi) AND (severe kidney impairment OR severe renal impairment OR end-stage renal disease OR dialysis OR renal failure OR ESRD OR renal insufficiency OR hepatorenal syndrome OR HRS). References listed in these literatures were also reviewed. Literature search was lastly updated on August 2018.

\section{Inclusion criteria}

Studies were included when following criteria was met:
1. Subject: HCV patients with stage 4 or 5 chronic kidney disease.

2. Intervention: SOF-based regimen.

3. Publication: articles, abstracts or letters.

\section{Exclusion criteria}

1. Patients with normal kidney function or early stage (1-3) CKD.

2. Number of enrolled patients or number of patients 12 weeks after treatment completion less than 10.

3. Insufficient data on SVR12/24, which is defined as undetectable HCV RNA 12 weeks (SVR12) or 24 weeks (SVR24) after treatment completion [12].

4. Insufficient $\mathrm{HCV}$ treatment combination information.

5. Case report.

\section{Data extraction}

Two authors independently extracted data of study design, patients demographics and characteristics, treatment strategy, SVR12/24, renal function, SAE, discontinuation due to AE. Disagreement was resolved by consensus.

\section{Quality assessment}

Newcastle-Ottawa scale (NOS) was applied to evaluate the quality and risk of bias of each study by two authors [15]. Studies were judged on three aspects, namely selection of study groups, the comparability of the groups and the exposure or outcome of participants. A score system was used for quality assessment in which a cumulative 79 score indicates high quality, 4-6 as fair quality.

\section{Data analysis}

SVR12/24 rate, SAE rate were combined and assessed by fixed effect model/random effect model via $\mathrm{R}$ software. Heterogeneity among studies was evaluated by $\mathrm{I}^{2}$ index, with value $>50$ implying substantial heterogeneity [16]. Fixed effect model was applied in the absence or minor heterogeneity, and random effect model was adopted for significant heterogeneity [17]. Comparison was made in subgroup analysis between studies that adopted full dose and decreased dose of sofosbuvir, RBV-containing and RBV-free regimen, studies that enrolled dialysisdependent and dialysis-independent patients, as well as studies of different geographic origin. The relative risk (RR) with 95\% CI was used to examine the impact of cirrhosis status to sustained virological response. We conducted sensitivity analysis to examine the robustness of primary findings. Publication bias was assessed by the Egger test for funnel plots asymmetry. 


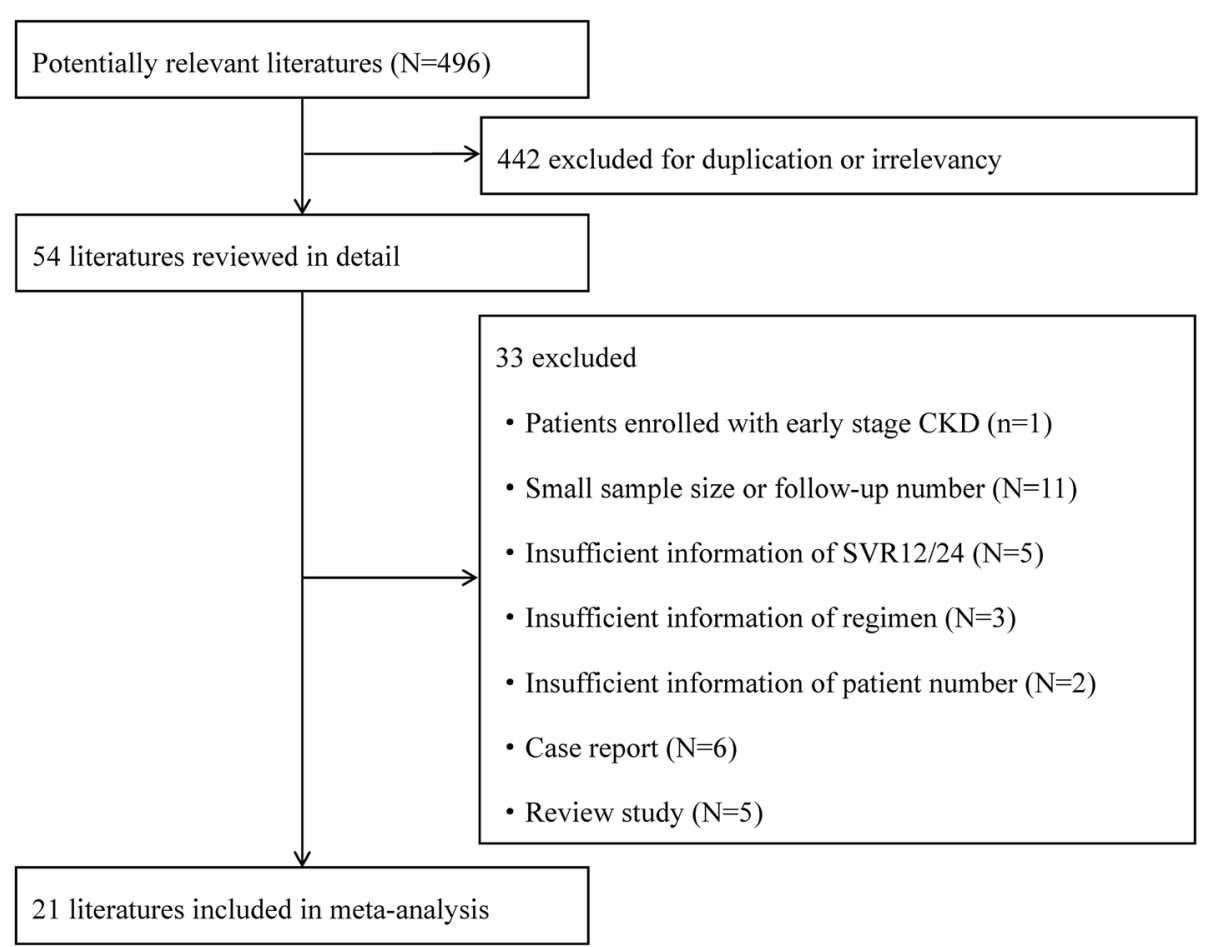

Fig. 1 Flow diagram of literature search and selection

\section{Results}

A total of 496 literatures were identified after preliminary search. Four hundred forty-two were excluded for duplication or irrelevancy. After further judgement by inclusion/exclusion criteria, final 21 studies were included for our review and meta-analysis, and IRB approval information were reported in 12 studies. Figure 1 shows the process of literature review and selection.

\section{Studies and patients' characteristics}

Twenty-one studies included manuscripts $(n=13)$, abstracts $(n=6)$ and letters $(n=2)$. All of them were prospective or retrospective cohort studies, with NOS score ranging 4-5 (two literatures scored 3). The absence of high quality is mainly due to absence of control arm. All of the studies met the inclusion criteria while one study enrolled patients with eGFR $<35 \mathrm{~mL} / \mathrm{min} / 1.73 \mathrm{~m}^{2}$ [18].

In total 717 patients were enrolled, including 419 (58.4\%) hemodialysis or peritoneal dialysis recipients. Patients' characteristics were shown in Table 1. Mean/ median age ranged from 35 to 62 among studies. Eighteen studies provided genotype information, overall GT 1 was predominant genotype (67\%), followed by GT 3 (20\%) and GT2 (8\%). Cirrhotic patient was eligible for most studies, and 4 studies included patients with decompensated cirrhosis. SOF-based regimen included: $\mathrm{SOF}+\mathrm{SMV} \pm \mathrm{RBV}, \mathrm{SOF}+\mathrm{PR}, \mathrm{SOF}+\mathrm{RBV}, \mathrm{SOF}+\mathrm{DCV} \pm$ $\mathrm{RBV}$ and $\mathrm{SOF} / \mathrm{LDV} \pm \mathrm{RBV}$, with varied administration of sofosbuvir: $400 \mathrm{mg}$ daily (QD), $200 \mathrm{mg}$ QD, $400 \mathrm{mg} / 48 \mathrm{~h}$, $400 \mathrm{mg}$ three times a week (TIW). Dose of sofosbuvir during treatment was rarely adjusted, except 2 patients increased from $200 \mathrm{mg}$ QD to $400 \mathrm{mg}$ QD after 4-6 weeks, and 3 reduced dosing due to sepsis, digestive discomfort or headache.

\section{Sustained virological response}

Per protocol (PP) analysis set was applied for sustained virological response analysis. The pooled SVR12/24 rate was $97.1 \%$ with random effect model (95\% CI 93.9-99.3\%, $\mathrm{I}^{2}=61 \%$ ) (Fig. 2). By aggregating dialysis-dependent patients $(n=306)$ and the others who were not on dialysis $(n=88)$ based on data available, we found significant difference of SVR12/24 between these two groups (95.1\% vs $100 \%, p=0.019$ ). (Additional file 1: Figure S1).

Studies with full sofosbuvir dose (400 mg QD) or decreased dose were compared for subgroup analysis. The difference between full dose (97.1, 95\% CI: 92.1-99.9\%) and decreased dose (96.2, 95\%CI: 88.3-100\%) was not significant $(p=0.72)$ (Additional file 2: Figure S2). Studies that applied single therapy of decreased-dose of sofosbuvir (i.e. $200 \mathrm{mg}$ QD or $400 \mathrm{mg} / 48 \mathrm{~h}$ or $400 \mathrm{mg}$ TIW) were further selected and compared, concluding that $200 \mathrm{mg}$ QD and $400 \mathrm{mg} / 48 \mathrm{~h}$ demonstrated similar treatment effect on total population $(100 \%$ vs $97.7 \%, p=0.30)$ (Additional file 3: Figure S3) [19-25]. For patients on dialysis, SVR12/24 was also comparable among varied doses of 


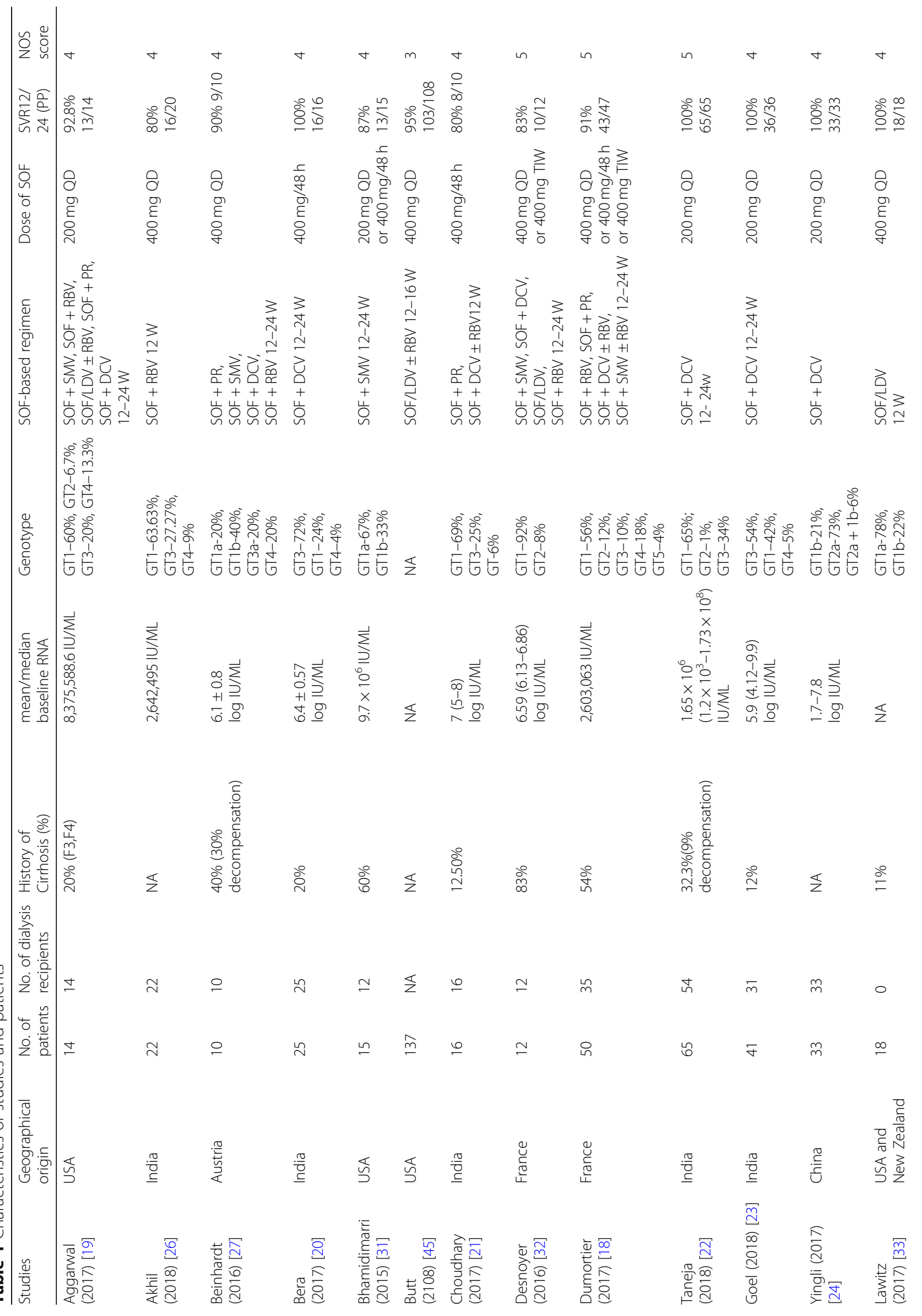


Li et al. Virology Journal

(2019) 16:34

Page 5 of 10

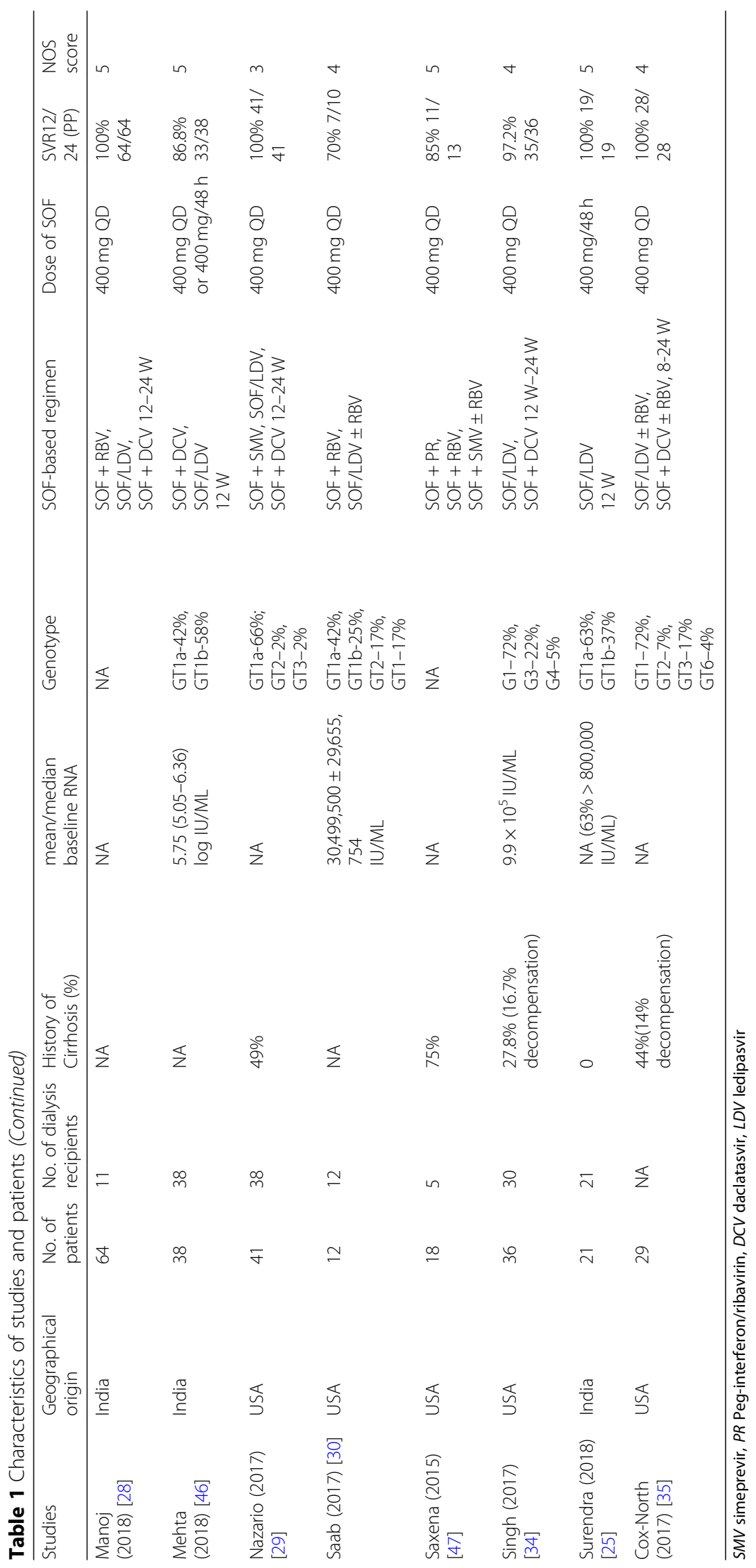




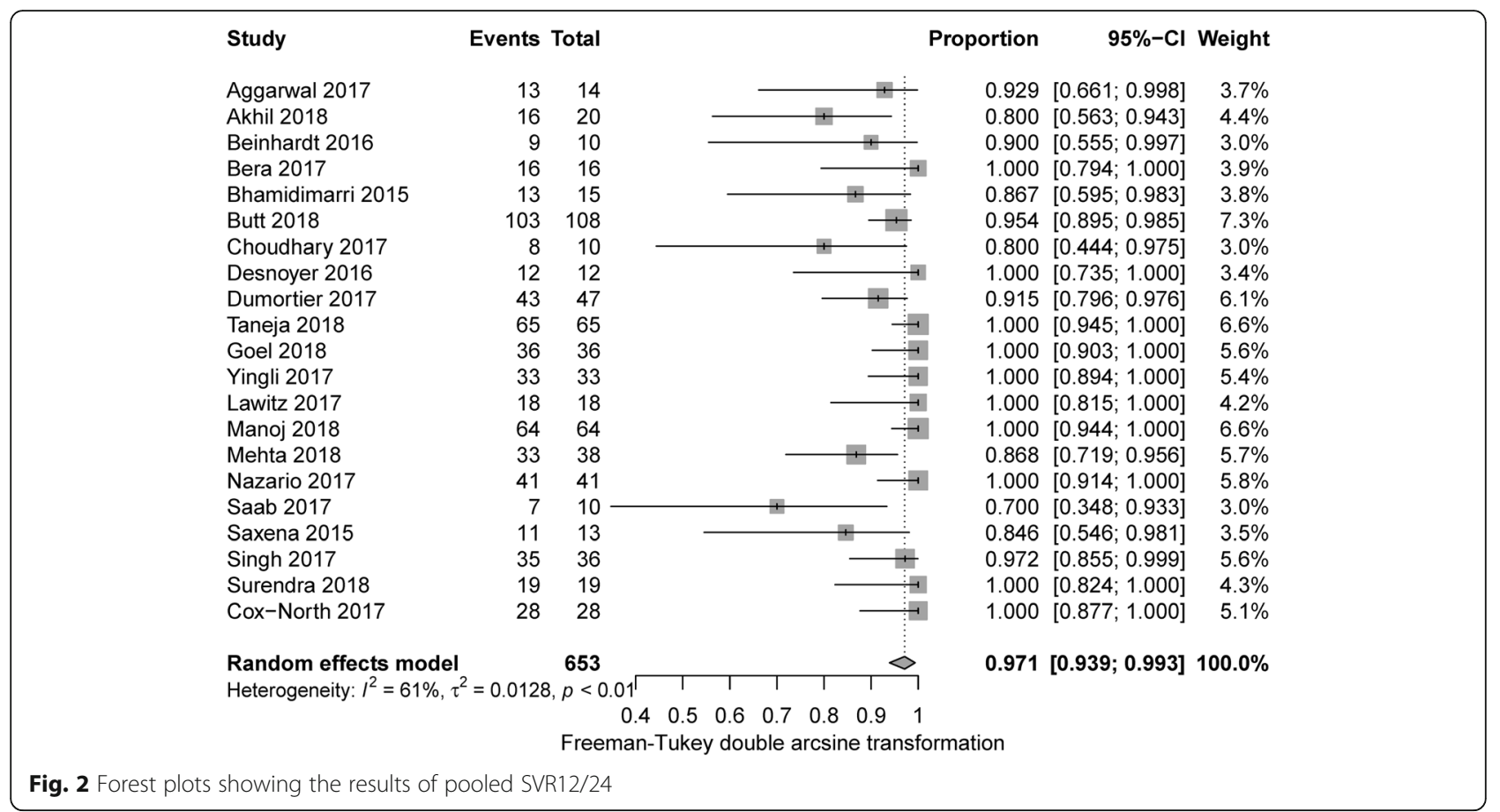

sofosbuvir $(p=0.25)$ (Additional file 4: Figure S4) [19-22, 24-30]. Ten studies adopted RBV-free regimen (SOF/LDV, SOF + DCV, SOF + SMV) with pooled SVR12/24 99.1\% (95\% CI: 96.2-100\%), higher than that of studies using RBV-containing therapy (94.0\%,95 CI: 87.5-98.6\%) $(p=0.035)$. Seven studies provided sufficient data for comparison between patients with or without cirrhosis [21-23, 29, 31-33]. Non-cirrhotic patients trended to have higher sustained virological response, while there was no significant difference between these two subgroups (RR 0.93, 95\% CI 0.85-1.02, $\mathrm{I}^{2}=33 \%$ ) (Fig. 3).

Most of the studies in this analysis originated from Asia and Norther America, and the pooled SVR12/24 was comparable among different regions $(p=0.15)$ (Additional file 5: Figure S5).

\section{Serious adverse event}

Information of SAE rate was provided in 16 studies, of which the pooled incidence was $4.8 \%$ (95\% CI $2.1-$ $10.3 \%, \mathrm{I}^{2}=60.0 \%$ ) (Fig. 4). SAE occurred in 5 studies, and 4 provided case description (Table 2). Subgroup analysis was conducted for studies with full dose and decreased-dose sofosbuvir, resulting no significant difference $(8.8 \%$ vs $2.9 \%, P=0.13)$.

\section{Change in renal function}

Four studies reported the dynamic of kidney function $[18,22,34,35]$, with detailed data before and after treatment (Table 3). Generally, eGFR was stable during treatment, and 2 cases reported discontinuation from hemodialysis due to eGFR improvement [35].

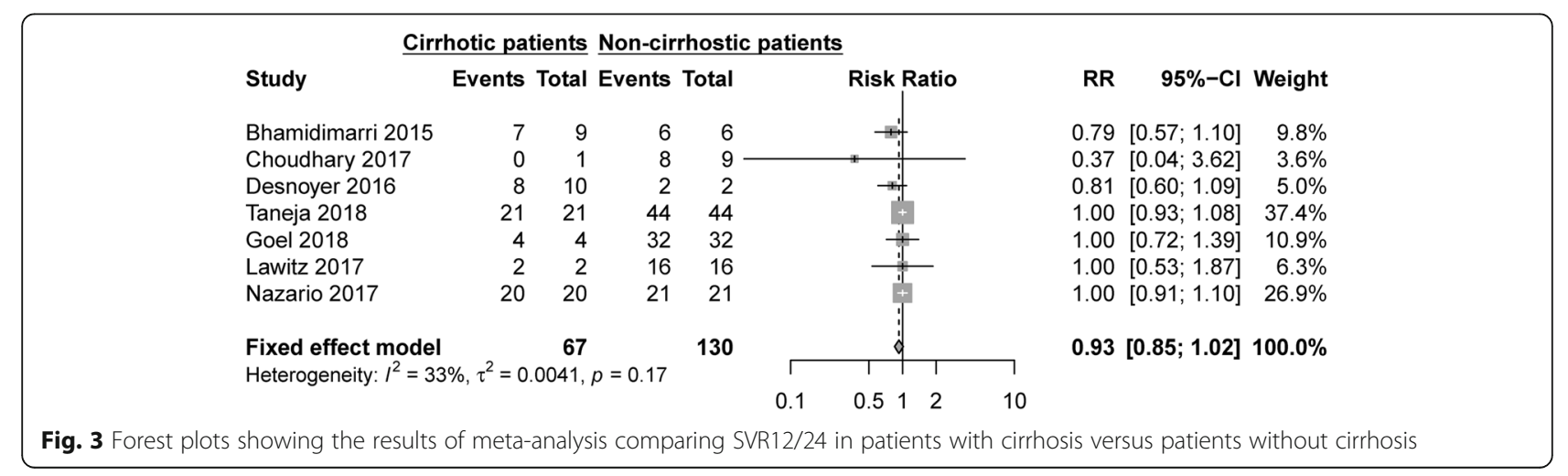




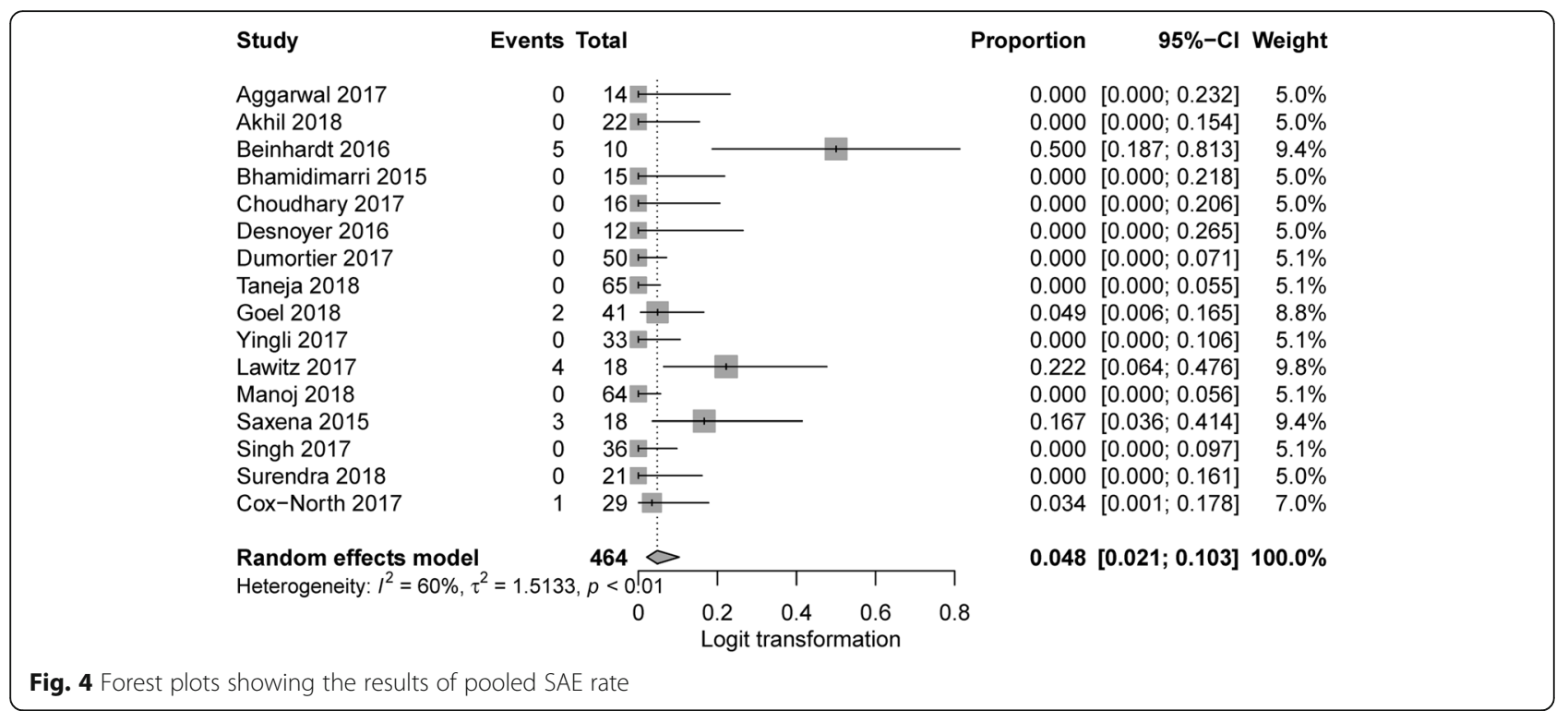

\section{Sensitivity analysis}

SVR12/24 of 13 manuscripts (PP analysis set) was aggregated, with pooled result of $97.0 \%$ (95\% CI: 92.4-99.7\%, $\mathrm{I}^{2}=66 \%$ ). 90.3\% SVR12/24 (95\% CI: 83.4-95.6\%, $\mathrm{I}^{2}=$ $84 \%)$ was resulted in intention to treat (ITT) analysis set for 21 studies. Not reaching SVR12 time point and lost follow-up were two major reasons for relative lower result in ITT analysis set.

\section{Publication bias}

$P$ value of Egger test for funnel plots asymmetry was not significant for ITT analysis set (0.537), and bordered significance level for PP analysis set (0.0498).

\section{Discussion}

Patients living with $\mathrm{HCV}$ infection and end-stage renal disease (ESRD) are special population for HCV treatment. Although current guidelines recommend the first-line therapies as elbasvir/grazoprevir, glecaprevir/ pibrentasvir, paritaprevir/ ritonavir/ombitasvir/dasabuvir (PrOD) $[12,13]$, unmet medical needs still exist at some cases (e.g. comorbidity of advanced liver disease, non-GT1 genotype) and when other therapies are not available. In these circumstances, sofosbuvir might be applied after weighing risk and benefit. In vivo, sofosbuvir undergoes intra-hepatic metabolism to form the pharmacologically active uridine analog triphosphate (GS-461203), which eventually results in ultimate

Table 2 Serious adverse events

\begin{tabular}{|c|c|c|c|}
\hline Study & No. of patients & No. of patients/events with SAE & Description of SAE (comments from investigator) \\
\hline \multirow[t]{5}{*}{ Beinhardt (2016) [27] } & \multirow[t]{5}{*}{10} & \multirow[t]{5}{*}{5 (5/5 on dialysis) } & 1 pt:: recurring peritonitis \\
\hline & & & 1 pt.: renal anemia \\
\hline & & & 1 pt:: graft failure after orthotopic liver transplantation (LOT) \\
\hline & & & 1 pt: cirrhosis due to HCV recurrence after OLT \\
\hline & & & 1 PT: pneumonia \\
\hline \multirow[t]{2}{*}{ Goel (2018) [23] } & \multirow[t]{2}{*}{41} & \multirow[t]{2}{*}{2 (0/2 on dialysis) } & 1 pt:: acute mild pancreatitis after renal transplantation \\
\hline & & & 1 pt.: worsening of ascites \\
\hline \multirow[t]{4}{*}{ Lawitz (2017) [33] } & \multirow[t]{4}{*}{18} & \multirow[t]{4}{*}{4 (0/4 on dialysis) } & 1 pt:: acute kidney injury and noncardiac chest pain \\
\hline & & & 1 pt:: dehydration and hypotension \\
\hline & & & 1 pt:: acute renal failure \\
\hline & & & $\begin{array}{l}1 \text { pt.: hypotension and synocope (no SAEs were considered } \\
\text { related to study drug) }\end{array}$ \\
\hline Saxena (2015) [47] & 18 & 3 & NA \\
\hline Cox-North (2017) [35] & 29 & 1 (1/1 on dialysis) & $\begin{array}{l}1 \text { pt: cardiac event (unable to draw any conclusions about the safety of } \\
\text { SOF regimens in those with underlying cardiac disease) }\end{array}$ \\
\hline
\end{tabular}


Table 3 Kidney function before and after treatment

\begin{tabular}{|c|c|c|c|c|}
\hline Study & No. of patients & $\begin{array}{l}\text { Mean/Median eGFR } \\
\left(\mathrm{mL} / \mathrm{min} / 1.73 \mathrm{~m}^{2}\right) / \\
\text { Serum Creatinine }(\mathrm{mg} / \mathrm{dL}) \\
\text { at baseline }\end{array}$ & $\begin{array}{l}\text { Mean/Median eGFR } \\
\left(\mathrm{mL} / \mathrm{min} / 1.73 \mathrm{~m}^{2}\right) / \\
\text { Serum Creatinine }(\mathrm{mg} / \mathrm{dL}) \\
\text { after treatment }\end{array}$ & $P$-value/Comments from investigator \\
\hline $\begin{array}{l}\text { Dumortier } \\
\text { (2017) [18] }\end{array}$ & 15 non-HD patients & eGFR 29.0 (20-34) & eGFR 27.0 (17-38) & $\begin{array}{l}\text { In non-HD patients, median eGFR was not } \\
\text { significantly modified during treatment. }\end{array}$ \\
\hline \multirow{2}{*}{$\begin{array}{l}\text { Taneja } \\
(2018)[22]\end{array}$} & \multirow[t]{2}{*}{11 pre-dialysis patients } & eGFR $24.84 \pm 3.96$ & eGFR $24.39 \pm 3.63$ & 0.82 \\
\hline & & Creatinine $2.52 \pm 0.35$ & Creatinine $2.56 \pm 0.36$ & 0.81 \\
\hline Singh(2017) [34] & 36 & eGFR $12.02 \pm 6.89$ & eGFR $12.33 \pm 6.10$ & 0.77 \\
\hline $\begin{array}{l}\text { Cox-North } \\
\text { (2017) [35] }\end{array}$ & $\begin{array}{l}\text { NA patients not } \\
\text { receiving dialysis }\end{array}$ & $\begin{array}{l}\text { eGFR } 22.2 \\
\text { creatinine } 3.1\end{array}$ & $\begin{array}{l}\text { eGFR } 20 \\
\text { creatinine } 3.3\end{array}$ & 1.0 \\
\hline
\end{tabular}

metabolite GS-331007 via dephosphorylation [36]. Sofosbuvir and GS331007 are mainly eliminated through kidney. Compared with subjects of normal renal function, area under the curve $\left(\mathrm{AUC}_{0 \text {-inf }}\right)$ of sofosbuvir and GS-331007 is 171 and 451\% higher for patients with $\mathrm{eGFR}<30 \mathrm{ml} / \mathrm{min}$ (not receiving hemodialysis) [11]. Desnoyer examined plasma concentrations of sofosbuvir (full dose) and GS331007 on hemodialysis patients and concluded they did not accumulate throughout the treatment course and between hemodialysis sessions [32]. Whether sofosbuvir and its metabolite accumulate in ESRD patients who are not on dialysis needs to be answered by further study.

Our meta-analysis included 21 studies, with a total of 717 patients. Pooled SVR12/24 was satisfying (97.1\%), similar or higher than that of non-SOF-based therapies [37-39]. Patients who were on dialysis also achieved a SVR12/24 as high as $95.1 \%$. Although it was lower than that of patients without dialysis, we assume it might not necessarily be the case given limited number of dialysis-free patients in our sub-analysis. Further welldesigned RCT are needed to conclude whether effect of sofosbuvir is influenced by dialysis. Aggregated SAE rate was $4.8 \%$, slightly higher than that in HCV infected patients with normal renal function $[8,9]$, which is reasonable since the patients involved in our meta-analysis had quite a few safety risk factors: old age, severe renal dysfunction, liver/renal transplant recipient, and advanced liver fibrosis. In another meta-analysis, SAE rate was $12.1 \%$ for direct-acting antivirals-based antiviral therapies in HCV/Stage 4-5 CKD patients [40]. Common SAEs included renal failure, cirrhosis complications, indicating special attention is needed on renal and liver function during treatment (Table 2).

Treatment strategy of SOF-containing therapy has been under broad discussion. Many physicians explored unconventional dose of sofosbuvir for safety concern, although there is no established pharmacokinetics profile for administration at $200 \mathrm{mg}$ QD, $400 \mathrm{mg} / 48 \mathrm{~h}$ or 400 mg three times a week. Our subgroup analysis suggests that regimen with full and decreased dose of sofosbuvir might be both considerable at acceptable SAE rate $(8.8 \%$ vs $2.9 \%)$ and high SVR12/24 (97.1\% vs $96.2 \%)$. We assume that sofosbuvir could be alternatively applied at a lower dose as half as normal or at a frequency extended to once every 2 days without compromising its efficacy significantly. While administering three times a week might not be optimal, given that median terminal half-lives of sofosbuvir and its metabolite GS331007 were 0.4 and 27 h (healthy subjects), and possible low SVR12/ 24 (60\% reported in very small sample size) [32]. Ribavirin should be used with caution, considering higher risk of anemia for RBV-containing regimen than RBV-free treatment. Anemia was the most frequently reported AE (6 to $43.7 \%$ ) in studies of our review, and RBV was included in almost all of these studies (8/9). Manoj reported that $65.4 \%(17 / 26)$ patients in SOF + RBV group developed anemia, and $30 \%$ had to discontinue ribavirin [28]. What is worth mentioning is that we found RBV-containing regimen reached lower SVR12/24. One of the reasons is likely to be tolerability issue of ribavirin, another reason might be potent combination drug with sofosbuvir in most RBV-free regimen, 9 studies applied SOF/LDV or SOF + DCV, and 7 achieved 100\% SVR12/24.

Kidney function deterioration is a concern for sofosbuvir usage. On one hand, there are few case reports proposed the correlation of nephrotoxicity and SOF-based therapy [41, 42], on the other hand, several large retrospective cohorts conclude SOF-based regimen does not introduce higher acute kidney injury for $\mathrm{HCV}$ patients compared to SOF-free treatment $[43,44]$. Studies that reported renal function in our review had generally stable eGFR and serum creatinine during treatment. Two SAE cases of AKI and acute renal failure were considered not related to study drug.

There are some limitations to our study. First, we could not perform subgroup analysis according to $\mathrm{HCV}$ genotype, CKD stage for lack of enough information. Second, geographical origin of studies enrolled is mainly USA and India, and that limits the representativeness of 
our analysis. Third, all of the studies were observational studies without control group, and most studies were of medium quality. Heterogeneity was substantial which might attribute to varied sample size and treatment therapy. Furthermore, some newly approved SOF-based therapy (e.g. SOF/VEL) was not included in this analysis for lack of evidence and analysis time frame. The factors above compromise the quality of this review. Prospective and well-controlled studies are expected in near future to provide more robust evidence.

\section{Conclusions}

This systematic review and meta-analysis evaluated SOF-based therapy for HCV infected patients with comorbidity of stage 4-5 CKD. Data from this study suggests satisfying sustained virological response and tolerance. For treatment strategy, both full and decreased dose of sofosbuvir could be appropriate. Caution is still needed at clinical practice.

\section{Additional files}

Additional file 1: Figure S1. Forest plots showing the results of subgroup analysis result of SVR12/24 in dialysis-dependent patients and patients not receiving dialysis. (PDF $6 \mathrm{~kb}$ )

Additional file 2: Figure S2. Forest plots showing the results of subgroup analysis result of SVR12/24 in studies applied full dose and decreased dose of sofosbuvir. (PDF $6 \mathrm{~kb}$ )

Additional file 3: Figure S3. Forest plots showing the results of subgroup analysis result of SVR12/24 in studies applied $200 \mathrm{mg}$ QD sofosbuvir or $400 \mathrm{mg} / 48 \mathrm{~h}$ sofosbuvir. (PDF $5 \mathrm{~kb}$ )

Additional file 4: Figure S4. Forest plots showing the results of subgroup analysis result of SVR12/24 in dialysis-dependent patients applying different doses of sofosbuvir. (PDF $6 \mathrm{~kb}$ )

Additional file 5: Figure S5. Forest plots showing the results of subgroup analysis result of SVR12/24 in patients originated from Asia, North America and Europe. (PDF $7 \mathrm{~kb}$ )

\section{Abbreviations}

AKI: Acute kidney injury; CKD: Chronic kidney disease; DCV: Daclatasvir; ESRD: End-stage renal disease; GFR: Glomerular filtration rate; HCV: Hepatitis C virus; HRS: Hepatorenal syndrome; ITT: Intention to treat; KDIGO: Kidney Disease Improving Global Outcomes; LDV: Ledipasvir; MELD: Model for endstage liver disease; NOS: Newcastle-Ottawa scale; PP: Per protocol; PR: Peginterferon/ribavirin; PRISMA: Preferred reporting items for systematic reviews and meta-analyses; PrOD: Paritaprevir/ ritonavir/ombitasvir/dasabuvir; RBV: Ribavirin; SAE: Serious adverse event; SMV: Simeprevir; SOF: Sofosbuvir; SVR: Sustained virological response; TIW: Three times a week

\section{Acknowledgements}

We would like to thank Dr. Jia, Mr. Wong, Mr. Xia and Mr. Lu for helpful consultation and comments on this manuscript.

\section{Funding}

This study was not supported by any commercial company or grants. No Gilead funding supports it.

\section{Availability of data and materials}

The datasets supporting the conclusions of this article is included within the article and its additional files.

\section{Authors' contributions}

QL and YL designed the study and take responsibility for the entire process; MSL conducted literature search, data extraction, quality assessment and draft writing; JC performed literature search, data extraction and quality assessment; ZXF analyzed the data and edited the paper. All authors have read and approved the final paper.

Ethics approval and consent to participate

Not applicable.

\section{Consent for publication}

Not applicable.

\section{Competing interests}

MSL works for Gilead while concurrently enrolled in Ph.D.

\section{Publisher's Note}

Springer Nature remains neutral with regard to jurisdictional claims in published maps and institutional affiliations.

\section{Author details}

${ }^{1}$ Xiangya School of Public Health, Central South University, 110 Xiangya Road, Changsha 410078, Hunan, China. ${ }^{2}$ Medical Affairs Department, Gilead Science, 179 Weifang Road, Shanghai 200122, China. ${ }^{3}$ Department of Liver Diseases, The Third People's Hospital of Shenzhen, 29 Bulan Road, Shenzhen 518114, Guangdong, China. ${ }^{4}$ Department of Infectious Disease, XiangTan City Central Hospital, 120 Heping Road, Xiangtan 411100, Hunan, China.

${ }^{5}$ Department of Infectious Disease, The Second Xiangya Hospital of Central South University, 139 Renmin Road, Changsha 410011, Hunan, China.

Received: 8 November 2018 Accepted: 1 March 2019

Published online: 14 March 2019

\section{References}

1. Kasuno K, Ono T, Matsumori A, Nogaki F, Kusano H, Watanabe H, Yodoi J, Muso E. Hepatitis C virus-associated tubulointerstitial injury. Am J Kidney Dis. 2003:41(4):767-75

2. WHO. GUIDELINES FOR THE CARE AND TREATMENT OF PERSONS DIAGNOSED WITH CHRONIC HEPATITIS C VIRUS INFECTION. 2018.

3. Fissell RB, Bragg-Gresham JL, Woods JD, Jadoul M, Gillespie B, Hedderwick SA, Rayner HC, Greenwood RN, Akiba T, Young EW. Patterns of hepatitis C prevalence and seroconversion in hemodialysis units from three continents: the DOPPS. Kidney Int. 2004;65(6):2335-42.

4. Fabrizi F, Dixit V, Messa P. Impact of hepatitis $C$ on survival in dialysis patients: a link with cardiovascular mortality? J Viral Hepat. 2012;19(9):601-7.

5. Fabrizi F, Takkouche B, Lunghi G, Dixit V, Messa P, Martin P. The impact of hepatitis $C$ virus infection on survival in dialysis patients: meta-analysis of observational studies. J Viral Hepat. 2007:14(10):697-703.

6. Lee JJ, Lin MY, Chang JS, Hung CC, Chang JM, Chen HC, Yu ML, Hwang SJ. Hepatitis $C$ virus infection increases risk of developing end-stage renal disease using competing risk analysis. PLoS One. 2014;9(6):e100790.

7. Afdhal N, Zeuzem S, Kwo P, Chojkier M, Gitlin N, Puoti M, Romero-Gomez M, Zarski JP, Agarwal K, Buggisch P, et al. Ledipasvir and sofosbuvir for untreated HCV genotype 1 infection. N Engl J Med. 2014;370(20):1889-98.

8. Feld JJ, Jacobson IM, Hezode C, Asselah T, Ruane PJ, Gruener N, Abergel A, Mangia A, Lai CL, Chan HL, et al. Sofosbuvir and Velpatasvir for HCV genotype 1, 2, 4, 5, and 6 infection. N Engl J Med. 2015;373(27):2599-607.

9. Lawitz E, Mangia A, Wyles D, Rodriguez-Torres M, Hassanein T, Gordon SC, Schultz M, Davis MN, Kayali Z, Reddy KR, et al. Sofosbuvir for previously untreated chronic hepatitis C infection. N Engl J Med. 2013;368(20):1878-87.

10. Isakova T, Nickolas TL, Denburg M, Yarlagadda S, Weiner DE, Gutierrez OM, Bansal V, Rosas SE, Nigwekar S, Yee J, et al. KDOQI US commentary on the 2017 KDIGO clinical practice guideline update for the diagnosis, evaluation, prevention, and treatment of chronic kidney disease-mineral and bone disorder (CKD-MBD). Am J Kidney Dis. 2017;70(6):737-51.

11. Gilead. sovaldi_pi. 2017

12. European Association for the Study of the Liver. Electronic address eee, European Association for the Study of the L. EASL recommendations on treatment of hepatitis C 2018. J Hepatol. 2018;69(2):461-511.

13. AASLD, IDSA. HCV Guidance: Recommendations for Testing, Managing, and Treating Hepatitis C. 2018. 
14. Moher D, Liberati A, Tetzlaff J, Altman DG, Group P. Preferred reporting items for systematic reviews and meta-analyses: the PRISMA statement. PLoS Med. 2009;6(7):e1000097.

15. Wells G, Shea B, O'Connell D, Peterson J, Welch V, Losos M, Tugwell P. The Newcastle-Ottawa scale (NOS) for assessing the quality of nonrandomised studies in meta-analyses; 2016.

16. Ryan R. Heterogeneity and subgroup analyses in Cochrane Consumers and Communication Review Group reviews: Planning the analysis at protocol stage; 2014.

17. Petitti DB. Approaches to heterogeneity in meta-analysis. Stat Med. 2001; 20(23):3625-33.

18. Dumortier J, Bailly F, Pageaux GP, Vallet-Pichard A, Radenne S, Habersetzer F, Gagnieu MC, Grange JD, Minello A, Guillaud O, et al. Sofosbuvir-based antiviral therapy in hepatitis $C$ virus patients with severe renal failure. Nephrol Dial Transplant. 2017;32(12):2065-71.

19. Aggarwal A, Yoo ER, Perumpail RB, Cholankeril G, Kumari R, Daugherty TJ, Lapasaran AS, Ahmed A. Sofosbuvir use in the setting of end-stage renal disease: a single center experience. J Clin Transl Hepatol. 2017;5(1):23-6.

20. Bera C, Das P, Pal S. Safety and efficacy of Sofosbuvir based regimen on patients with end stage renal disease - a single Centre experience. J Clin Exp Hepatol. 2017;7:S29. https://doi.org/10.1016/j.jceh.2017.05.061

21. Choudhary NS, Kumar A, Bodh V, Bansal SB, Sharma R, Jain M, Saigal S, Saraf N. Efficacy and safety of sofosbuvir-based regimens in chronic hepatitis $C$ patients on dialysis. Indian J Gastroenterol. 2017;36(2):113-6.

22. Taneja S, Duseja A, De A, Mehta M, Ramachandran R, Kumar V, Kohli HS, Gupta KL, Dhiman RK, Chawla Y. Low-dose Sofosbuvir is safe and effective in treating chronic hepatitis $C$ in patients with severe renal impairment or end-stage renal disease. Dig Dis Sci. 2018;63(5):1334-40.

23. Goel A, Bhadauria DS, Kaul A, Verma P, Mehrotra M, Gupta A, Sharma RK, Rai P, Aggarwal R. Daclatasvir and reduced-dose sofosbuvir: an effective and pangenotypic treatment for hepatitis $C$ in patients with eGFR $<30 \mathrm{ml} / \mathrm{min}$. Nephrology (Carlton). 2019 Mar;24(3):316-21. https://doi.org/10.1111/nep.13222.

24. He Y, Chen T, Zhao Y. Safety, efficacy and tolerance of half-dose sofosbuvir plus daclatasvir in treatment of acute hepatitis $C$ infection in patients with end-stage renal disease on hemodialysis: a prospective, single-center, openlabel study. Hepatology. 2017;66:583A.

25. Surendra M, Raju SB, Sridhar N, Vijay Kiran B, Rajesh G, Anvesh G, Raju N. Ledipasvir and Sofosbuvir for untreated HCV genotype 1 infection in end stage renal disease patients: a prospective observational study. Hemodial Int. 2018;22(2):217-21.

26. Akhil MS, Kirushnan B, Martin M, Arumugam K, Ganesh Prasad NK, Ravichandran R. Sofosbuvir-based treatment is safe and effective in Indian hepatitis $C$ patients on maintenance haemodialysis: a retrospective study. Nephrology (Carlton). 2018;23(5):446-52.

27. Beinhardt S, Al Zoairy R, Ferenci P, Kozbial K, Freissmuth C, Stern R, Stattermayer AF, Stauber R, Strasser M, Zoller H, et al. DAA-based antiviral treatment of patients with chronic hepatitis $C$ in the pre- and postkidney transplantation setting. Transpl Int. 2016;29(9):999-1007.

28. Manoj K, Nayak SL, Gupta E, Kataria A, Sarin SK. Generic sofosbuvir-based direct-acting antivirals in hepatitis $C$ virus-infected patients with chronic kidney disease. Liver Int. 2018;38:2137-48.

29. Nazario HE, Modi AA, Ndungu M, Ramirez R, Tujague L, Weinstein JS. Excellent cure rates in largest ESRD patient cohort who completed treatment with full dose, daily sofosbuvir-based regimens. J Hepatol. 2017;66(1):S507. https://doi. org/10.1016/S0168-8278(17)31414-9

30. Saab S, AJ M, NB S, Choi G, Durazo FA, ME-K M, Han SB, Busuttil RW. Use of Sofosbuvir-based treatment of chronic hepatitis $C$ in liver transplant recipients on hemodialysis. J Clin Gastroenterol. 2017;51(2):167-73.

31. Bhamidimarri KR, Czul F, Peyton A, Levy C, Hernandez M, Jeffers L, Roth D, Schiff E, O'Brien C, Martin P. Safety, efficacy and tolerability of half-dose sofosbuvir plus simeprevir in treatment of hepatitis $C$ in patients with end stage renal disease. J Hepatol. 2015;63(3):763-5.

32. Desnoyer A, Pospai D, Le MP, Gervais A, Heurgue-Berlot A, Laradi A, Harent S, Pinto A, Salmon D, Hillaire S, et al. Pharmacokinetics, safety and efficacy of a full dose sofosbuvir-based regimen given daily in hemodialysis patients with chronic hepatitis C. J Hepatol. 2016;65(1):40-7.

33. Lawitz E, Landis CS, Maliakkal BJ, Bonacini M, Ortiz-Lasanta G, Zhang J, Mogalian E, De-Oertel S, Osinusi AO, Brainard DM, et al. Safety and Efficacy of Treatment with Once-Daily Ledipasvir/Sofosbuvir (90/400 mg) for 12 Weeks in Genotype $1 \mathrm{HCV}$-Infected Patients with Severe Renal Impairment. Hepatology. 2017;66-1(Suppl 1587):848A.
34. Gordon SC, Ahmed A, Saab S, Dieterich DT, Wong RJ, Kugelmas M, Brown KA, Younossi ZM. Health Outcomes Associated with Sofosbuvir-based Single-Tablet Regimens for Initial and Re-treatment of Chronic Hepatitis C in the US. Hepatology. 2017:66-1(Suppl 1181):635A.

35. Cox-North P, Hawkins KL, Rossiter ST, Hawley MN, Bhattacharya R, Landis CS. Sofosbuvir-based regimens for the treatment of chronic hepatitis $C$ in severe renal dysfunction. Hepatol Commun. 2017;1(3):248-55.

36. McQuaid T, Savini C, Seyedkazemi S. Sofosbuvir, a significant paradigm change in HCV treatment. J Clin Transl Hepatol. 2015;3(1):27-35.

37. Miyazaki R, Miyagi K. Effect and safety of Daclatasvir-Asunaprevir combination therapy for chronic hepatitis C virus genotype $1 \mathrm{~b}$-infected patients on hemodialysis. Ther Apher Dial. 2016;20(5):462-7.

38. Pockros PJ, Reddy KR, Mantry PS, Cohen E, Bennett M, Sulkowski MS, Bernstein DE, Cohen DE, Shulman NS, Wang D, et al. Efficacy of directacting antiviral combination for patients with hepatitis $C$ virus genotype 1 infection and severe renal impairment or end-stage renal disease. Gastroenterology. 2016;150(7):1590-8.

39. Roth D, Nelson DR, Bruchfeld A, Liapakis A, Silva M, Monsour H Jr, Martin P, Pol S, Londono MC, Hassanein T, et al. Grazoprevir plus elbasvir in treatment-naive and treatment-experienced patients with hepatitis $C$ virus genotype 1 infection and stage 4-5 chronic kidney disease (the C-SURFER study): a combination phase 3 study. Lancet. 2015;386(10003):1537-45.

40. Li T, Qu Y, Guo Y, Wang Y, Wang L. Efficacy and safety of direct-acting antivirals-based antiviral therapies for hepatitis $C$ virus patients with stage 45 chronic kidney disease: a meta-analysis. Liver Int. 2017;37(7):974-81.

41. Gadde S, Lee B, Kidd L, Zhang R. Antineutrophil cytoplasmic antibodies crescentic allograft glomerulonephritis after sofosbuvir therapy. World J Nephrol. 2016;5(6):547-50.

42. Wanchoo R, Thakkar J, Schwartz D, Jhaveri KD. Harvoni (Ledipasvir with Sofosbuvir)-induced renal injury. Am J Gastroenterol. 2016;111(1):148-9.

43. Durand F, Pianko S, Ni L, De-Oertel S, McNally J, Brainard DM, McHutchison JG, Schiff ER, Colombo M. Safety of Sofosbuvir-Based Regimens for the Treatment of Chronic HCV Infection in Patients with Mild or Moderate Renal Impairment. Hepatology. 2016;64-1(Suppl 867):428A.

44. Telep L, Brown A, Brainard DM, Chokkalingam AP. Assessment of risk of acute kidney injury associated with exposure to sofosbuvir-containing HCV treatment regimens and HCV infection. Hepatology. 2016;64-1(Suppl 770):380A.

45. Butt AA, Ren Y, Puenpatom A, Arduino JM, Kumar R, Abou-Samra AB. Effectiveness, treatment completion and safety of sofosbuvir/ledipasvir and paritaprevir/ritonavir/ombitasvir + dasabuvir in patients with chronic kidney disease: an ERCHIVES study. Aliment Pharmacol Ther. 2018;48(1):35-43.

46. Mehta R, Desai K, Kabrawala M, Nandwani S, Shah J, Desai N, Parekh V. Preliminary experience with sofosbuvir-based treatment regimens for patients dependent on hemodialysis. Indian J Gastroenterol. 2018;37(1):72-3.

47. Saxena V, Koraishy FM, Sise M, Lim JK, Chung RT, Liapakis A, Nelson DR, Schmidt M, Fried MW, Terrault N. LP08 : Safety and efficacy of sofosbuvircontaining regimens in hepatitis $C$ infected patients with reduced renal function: Real-world experience from HCV-target. J Hepatol. 2015:62:S267. https://doi.org/10.1016/S0168-8278(15)30162-8

Ready to submit your research? Choose BMC and benefit from:

- fast, convenient online submission

- thorough peer review by experienced researchers in your field

- rapid publication on acceptance

- support for research data, including large and complex data types

- gold Open Access which fosters wider collaboration and increased citations

- maximum visibility for your research: over $100 \mathrm{M}$ website views per year

At $\mathrm{BMC}$, research is always in progress.

Learn more biomedcentral.com/submissions 